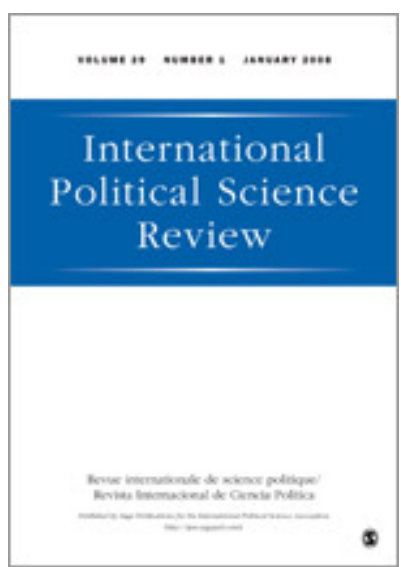

\title{
Deliberative democracy in the age of perpetual crisis
}

\begin{tabular}{|c|l|}
\hline Journal: & International Political Science Review \\
\hline Manuscript ID & IPSR-19-0225.R1 \\
\hline Manuscript Type: & Invited Review \\
\hline Category (Topics): & $\begin{array}{l}\text { Deliberative Democracy, Normative political theory, Democratic theory, } \\
\text { Mini-publics, Public sphere, Liberal democracy }\end{array}$ \\
\hline NormativePoliticalTheory, PCM PoliticalCommunication, PRT \\
Participation
\end{tabular}

\section{SCHOLARONE" Manuscripts}




\title{
Deliberative democracy in the age of perpetual crisis
}

\begin{abstract}
When polarised opinion turns democratic norms into a source of paralysis, too many voters are driven to strongmen who have no use for such principles other than as a veneer to decorate their grab for power. But democracy is not helpless. Institutions struggling with polarisation must innovate. To stay true to their democratic justification, they should adapt in the direction of a better exercise of reasoned disagreement - never a silencing of it.
\end{abstract}

Deliberative democracy has now made it into the mainstream. The above statement was not taken from the pages of a book on normative political theory. It was published in the opinion pages of The Financial Times (August 11, 2019) in a statement by the Editorial Board entitled 'Deliberative Democracy is just what politics needs.' Where once it would have been remarkable for a broadsheet to advance the case for deliberative democracy, opinion pieces proffering similar conclusions now appear regularly in major publications. 'Deliberative democracy may help to break the deadlock' said the Editorial of The Guardian (December 21, 2018) in reference to Brexit. A former MP wrote an op-ed in The Hindu declaring the enrichment of the country's deliberative democracy as the essence of the mandate in the 2019 Indian elections (January 28, 2019). The South China Morning Post published letters to the editor calling for a Citizens' Assembly as Hong Kong's last best hope in its standoff against China (August 2 and 10, 2019).

These developments signal the momentum behind deliberative democracy as its core ideas enter and reshape contemporary political vocabulary. Today, deliberative democracy-an ideal where 'people come together, on the basis of equal status and mutual respect, to discuss political issues they face and, on the basis of those discussions, decide on the policies that will affect their lives' (Bächtiger, Dryzek, Mansbridge and Warren, 2018: 2) - is being put to a test in multiple fronts. As a theoretical approach, deliberative democracy is challenged to diagnose the problems faced by liberal democracies, including the rise of incivility, political polarisation, the normalisation of disinformation and the growing appeal of simplistic solutions to complex problems. Some scholars have interpreted the crisis of democracy as a crisis of communication (Dryzek et al, 2019), in the absence of norms such as listening, reflection, and justification that are essential to the proper functioning of democratic institutions (Ercan et al, 2019).

Meanwhile, as an empirical endeavour, deliberative democracy is increasingly under pressure to investigate how micro-political deliberative forums and macro-institutional reforms can build capacity for citizens and decision-makers to engage in inclusive, authentic, and consequential communication. While scholarly research has demonstrated how small-scale, carefully designed deliberative forums can alter citizens' political behaviour, questions remain about what exactly deliberative democracy can offer to the broader challenges that define our time-from the rise of illiberal populism to the realities of climate change to the unmitigated power of big tech, to public health emergencies with global reach.

In this survey article, we take stock of recent developments in the field to assess how deliberative democracy has evolved to respond to some of these challenges. Our approach is both descriptive and reflective. We describe deliberative democracy as a field of research that 
has evolved to become (1) assertive in practice, (2) precise in theory, (3) global in reach, and (4) ambitious in empirical research. While some of these features are evident in earlier iterations of deliberative democracy, we argue that the intersection of these four qualities define the character of the field today. In each of these facets of deliberative democracy, we reflect on the extent to which the field has responded to conceptual and empirical challenges, and identify the field's shortcomings that warrant further attention. We conclude by drawing attention to research imperatives that will shape the field in years to come.

\section{Assertive in practice}

Deliberative democracy is long said to have 'come of age' as a practical instead of a counterfactual ideal (Bohman, 1998). Responding to critiques that deliberative democracy reflects a naïve vision of politics, the field has embraced realism without surrendering its normative commitments. It emphasised the value of public justification without demanding consensus, acknowledged that citizens may be 'good group problem solvers even if we are poor solitary truth seekers' (Chambers, 2018a: 36), and recognises the challenges of promoting deliberation in a macropolitical environment constrained by hyper-partisanship, a trust deficit, cognitive bias, and profit-driven media. Deliberative practice in the past decade has taken on the challenge of proposing wide-reaching reforms in an imperfect world.

The assertiveness of deliberative democracy's reform agenda is pronounced mainly in the surge in popularity of deliberative mini-publics as mechanisms for collective decision-making and problem-solving. Mini-publics are carefully designed forums where a group of citizens, selected by lottery to represent the microcosm of society, are charged to learn about an issue, weigh the evidence, exchange and reflect on each other's reasons with a view of putting forward a recommendation or a common statement about the topic at hand (see Setälä and Smith 2018). Mini-publics can be as small as fourteen people as in the case of citizen juries or go up to over a hundred as in the case of citizens assemblies.

The practice of deliberation at different levels of governance has provided robust responses to various criticisms against deliberation. It has found that large-scale deliberative forums, when properly designed, build capacity for argumentation and reflective judgment among a diverse group of citizens (see Bächtiger et al 2019), contrasting with scepticism about citizen competence (e.g. Achen and Bartels 2016; Brennan 2016). One of the key studies in this area is Paromita Sanyal and Vijayendra Rao's (2018) recent work on India, home of the world's largest deliberative assemblies. Using surveys, direct observations, and ethnography, Sanyal and Rao demonstrate that even impoverished and illiterate communities can take part in deliberation on a range of topics, from taxes to water supply. This research demonstrates that citizens, even in a caste society, can break the constraints of social hierarchies, albeit temporarily, when procedures for voice and accountability are in place. Citizens, in other words, are capable group deliberators when there are opportunities for them to learn, reflect, and express their views.

Evidence of deliberation's transformative power has inspired what the OECD refers to as a 'deliberative wave' taking place in Europe, where the number of deliberative processes recorded in their database surged from six mini-publics linked to public decision-making recorded in 2006-2010 to 25 from 2016 to 2019 among member countries (OECD, 
forthcoming). These mini-publics are under no illusion that deliberation is a panacea for solving intractable conflict or complex policy issues, yet there is growing confidence in the power of innovations like these to mitigate aforementioned issues of unequal citizen competence, partisanship and status inequality, among others.

The Irish Citizens' Assembly is often regarded as a game changer in this regard. In the middle of heated debates on moral issues about same sex marriage and abortion, the Citizens Assembly served as circuit breaker for a representative sample of citizens to listen to testimonies and expert evidence, and deliberate with their peers, including representatives of political parties, to create recommendations that could influence a referendum on these issues. The Irish case is not the first to link a citizens' assembly to a referendum. The British Columbia's Citizens Assembly on Electoral Reform predates it by a decade (Warren and Pearse, 2008) while the Citizens' Initiative Review has been going on for over 30 years (Gastil and Knoblock 2020). What's pathbreaking about the Irish case, however, is it demonstrates how a citizens' assembly can feed into parliamentary deliberations and shape the character of public discourse and collective decision-making on deeply divisive issues (Farrell and Suiter 2019). Elsewhere in Europe, citizens' assemblies are being convened at an incredible pace. Citizens assemblies on climate change are unfolding in France, Germany and the United Kingdom. The Polish city of Gdansk assembled citizens to deliberate over four weekends to provide recommendations on flooding mitigation. The citizens' assembly was an assertive exercise of democratic participation amidst the popularity of the conservative right-wing Law and Justice Party (PiS) that has undermined the rule of law, media freedom and checks and balances. Meanwhile, 100 people in Scotland were charged to deliberate for six days about the country they are seeking to build at a time when discussions on Scottish independence are heating up. In Belgium, a permanent citizens' assembly was institutionalised in the German-speaking region to propose agenda for legislation and serve as a resource for the panel by deliberating on divisive political issues. The institutionalisation of a citizens' assembly in deeply divided Belgium is no easy feat, for political parties transcended their ideological differences to endorse this policy.

These examples, among many others, demonstrate the confidence of deliberative democracy in creating spaces for meaningful discourse despite moral disagreements, status inequality, and the return of illiberalism. Accompanying the rise of populism are large-scale experiments in deliberation that give voice to ordinary citizens who otherwise felt left behind by traditional forms of participation like elections and party membership (see Chwalisz 2015). The appeal of these initiatives rests on empirical claims of what deliberation can achieve, but also a recognition that many of its design features are themselves products of deliberation. The growing community of deliberative practitioners around the world have now formed a network called Democracy R\&D where issues about sampling and random selection, integrity of deliberative processes, as well as the complexities of impact and evaluation are critically discussed in online discussion boards, Zoom learning calls, and annual meetings (see https://democracyrd.org/). Knowledge about deliberative democracy is no longer just produced in the confines of academic research but generated based on reflection on practical experiences of organisations commissioned to run these events (see newDemocracy 2019).

While there are many developments in the field of deliberative practice, new debates are emerging. One of the more contentious debates concerns the reach of mini-publics beyond 
the confines of the forum. Should mini-publics be given decision-making powers or should their reasoned recommendations serve as one of many considerations in collective decisionmaking (see Lafont 2019)? As the demand for deliberative mini-publics grows, how can the industry of consultants and practitioners be held accountable to the highest standards of integrity (see Lee, 2014)? What about their instrumental use by the state for non-deliberative forms of legitimation? How about deliberative democracy's links to institutions of representative democracy? What is the role of deliberation in political parties (Wolkenstein 2019) and enhancing the relationship between elected representatives and their constituencies (Neblo, Esterling, Lazer 2018)? Is deliberative democracy a replacement to institutions of representative democracy or are mini-publics tools to regain these institutions' legitimacy (see Sintomer 2018)? These, to date, are open questions, which will shape the character of deliberative practice in the years to come.

\section{Precise in Theory}

Over recent years, a lively set of debates have emerged among deliberative theorists concerning the precise nature of deliberation. Early normative political theory took a restrictive view of deliberation, defining it as a process of reason giving culminating in political decision (Cohen 1989). Numerous scholars-deliberative as well as difference democratspointed out that deliberation so understood was exclusionary. Progressively more forms of speech and communication were admitted to deliberation. Deliberation could thus be emotional, it could involve the use of rhetoric, story-telling, humour, testimony, greetings, and so on (Gormley 2019). Goodman (2018) even advocated for "unruly and excessive" speech where it has the capacity to disrupt the negative effects of the norms of civility. But all this produced a backlash. There arose the concern that if all forms of communication were admitted to deliberation, then the concept loses its meaning. As Goodin (2018) puts it, if deliberation is everything, perhaps it is nothing.

Deliberative theorists respond to this challenge, reworking deliberative theory to integrate these critiques, while maintaining its core feature. For example, Mansbridge (2015) has sought to address concept stretching by proposing a minimalist concept of deliberation. Deliberation, she argues, should be defined such that its constitutive features are separated from the normative demands we might make of it. On these terms, communication is deliberative where it is characterized by mutuality between speakers, generates reflection among them, and is oriented to matters of common concern. From here we can identify particular kinds of deliberation, depending on the normative standards we might hold them to, and in light of the institutional contexts in which they are undertaken. There is, for example, authoritarian deliberation where the state highly controls the deliberative process while providing citizens some space for democratic expression (He and Wagenaar 2018) or ritual deliberation where participants cannot be seen to be changing their minds, as in the case of parliamentary debates (Tanasoca and Sass 2019). Recently, Chung and Duggan (2020) proposed a formal theory of deliberation, distinguishing three modes of deliberation as (1) myopic discussion where positions on an issue are examined and weighed in a free flowing manner; (2) constructive discussion where deliberation unfolds in an 'argument-climbing dynamic' and (3) debate between opposing parties where each participant employs rhetorical tactics to advance one's position. Such formal analysis identifies how different forms of 
democratic deliberation can fail or succeed and the extent to which democratic legitimacy can be conferred on their outcomes.

A consequence of recognising the many forms of deliberation is the different standards by which they should be evaluated, depending on their functions and the constraints they face. Bächtiger and Parkinson (2018), for example, describe deliberation and deliberativeness as contingent on goals and contexts, performative in the sense that deliberation can be mixed with various forms of communication, and distributed where deliberative qualities 'are not concentrated in one location or at one moment but dispersed over space and time' (Bächtiger and Parkinson 2018: 15). This kind of argument finds resonance in the work of theorists such as Laydet (2015) who proposes that parliaments-often thought of as defining deliberative institutions-should be evaluated not vis-a-vis the quality of their own deliberation but in terms of their contribution to a wider process of public deliberation. Parliaments should frame debates, set out key positions, subject these positions to scrutiny. We should only expect that arguments made there are well-justified and that respect is shown to the opposition. In another piece arguing for the relaxation of familiar demands placed on deliberation, Moore (2018) shows that in many kinds of deliberative forums, participants should be granted anonymity for both epistemic and normative reasons. A crucial contribution of this specification of deliberation is distinguishing deliberative acts from other kinds of communication, which serve important non-deliberative functions within a democracy, and which are often intermingled with deliberation in complex ways. As such, the study of all political communication should be undertaken in light of the specific goals it is directed towards, not merely certain normative standards which political theory brings to it.

There remain important theoretical debates around what deliberation is, how it works and what it yields at different scales and in different institutional contexts. As deliberative democracy attempts to be more precise in its theoretical categories, questions emerge about its core normative commitments and its constitutive features. There is also work to be done to develop a link between how the process of public deliberation can generate substantive outcomes that can respond to the crisis of liberal democracy, whether deliberative democracy needs to be bolder in its demands for institutional reform and instead advocate for radical overhaul of the representative system of democracy (see Landemore 2020). If deliberative democracy is to respond to the crisis of democracy, conceptual refinement and debates about institutional reform must continue.

\section{Global in reach}

Deliberative theory has also developed in response to critiques that its application may be limited because it emerged the particularistic experience of Western European modernity, or from the greater Western tradition (see Min, 2009). To be sure, deliberative democrats sometimes trace their intellectual heritage through the Western canon, beginning with Aristotle and passing through a chain of luminaries, including Mill, Rousseau, Kant, Dewey and others (Chambers 2018). Self-descriptions of this kind are hardly unique in political theory, though often spurious. There is certainly no single, continuous lineage of deliberative theory. Rather, prominent thinkers have been enrolled into deliberative theory wherever they provide philosophical insight into the themes and problems which define the field. In this regard, the critique of deliberative democracy as being ethnocentric seems lacking in 
imagination. There is nothing to stop deliberative theory from treating non-Western political thought as a source of insight where fashioning deliberative ideals, practices and institutions-indeed, this very undertaking is now well underway. Deliberative democracy, in other words, is one that is global in reach. Its knowledge production and political practice has plural centres.

There are many well-established sources for deliberative principles and ideals outside 'the West.' Sen (2005) suggests that there are deliberative practices pervasive within South Asia and find their roots in diverse religious traditions. Sass and Dryzek (2014) take this argument a step further. They suggest that collective deliberation is basic to all human groups, and aids their survival, but that deliberation manifests in very different ways depending on the cultural and normative meaning afforded to it in specific contexts. Who can deliberate, on what terms, by what means, to what ends-these are all matters of considerable variation. Given the pervasiveness of deliberation, it should not be surprising that there are alternative sources of deliberative ideals. In South Asia, Gandhi, Amdedkar, Ashoka and others provide normative resources for those who would promote a deliberative politics (Mantena, 2012). Across Africa (Ani, 2014) there are diverse forms of group organization and conceptualisations of the place of voice therein. In China and Japan, typically characterized as hierarchical societies, there are principles and practices which could form the basis of a civilizationally distinctive public sphere (Tan, 2014). Scholars too have begun to reflect on Indigenous cultures, past and present, as regards their use of deliberative practices in conflict resolution and group decision-making (Hébert, 2018; Urfalino, 2014). Much of this work has been undertaken in the context of comparative political theory, which enabled the exchange between deliberative theory and other traditions (Williams and Warren, 2014).

While the citizens assemblies and other deliberative forums discussed thus far have been concentrated in Europe and the European settler states, there has been experimentation and indeed institutionalization of deliberative forums in other national contexts. In the earlier section, we identified gram sabhas (village assemblies) in India which has affected the lives of nearly 900 million people. In Mongolia, the Parliament called for its first-ever deliberative poll, where 669 randomly selected citizens convened in Ulaanbaatar to discuss the future of the constitution (Fishkin 2019). Deliberation has also been systematically incorporated into local governance structures in numerous Chinese provinces (He and Warren, 2011). This may signal a recognition of the that state's own tragic failure to listen to the voices of ordinary people while pursuing vast development projects or it may represent a mechanism which provides the Chinese Communist Party stronger control over restive groups. Indeed, it may perform both these functions. Across South America too new forms of participatory governance prioritise inclusive deliberation (Avritzer, 2005). But here too is reason for concern. Brazil, by way of example, may be among the most deliberative democracies, but this provided little resistance to the state's lurch to authoritarianism. In this regard, the study of deliberation in fragile democracies and authoritarian contexts demands that deliberative democrats evaluate the promise, scope, and effects of deliberation in the hard light of day (see Shaffer and Black, 2018).

The reach of deliberation has grown markedly over in recent years in a number of senses. In the first instance, this has occurred because deliberative democrats have taken growing interest in the practice of deliberation seen across an ever-wider variety of societies, historical 
and contemporary. This expansive orientation represents a marked shift from earlier scholarship which, for the most part, limited its empirical focus on established Western democracies and the Western philosophical tradition. In this respect, the criticism of deliberation as being ethnocentric and bourgeois has been productive. It has provoked a wider discussion across national and civilizational contexts concerning both the normative justification of deliberation and the design of contextually-sensitive institutions that would facilitate empowered and inclusive discourse. To be sure, no tradition of normative political thought is truly global, or universal. But recent deliberative theory displays a global and universal ambition, one that is approached through engaging with ever wider circles of difference in a process of learning that enlarges the tradition and (ideally) the traditions with which it engages.

\section{Ambitious in empirical research}

That deliberative democracy has become assertive in practice, precise in theory and global in reach is a manifestation of the field's intellectually ambitious disposition towards empirical research. While scholars including Habermas (2006) himself were initially worried about the application of a normative theory in empirical research, empirical scholars have shown a variety of ways normative theory can interact with and guide the empirical work on deliberation both within micro-deliberative forums and the macro-political deliberative system.

The high ambition of the empirical research agenda is manifested in two key ways. First, it is reflected in the way the field has embraced methodological pluralism to offer multilayered characterisations of deliberation. Apart from drawing on social science methods such as surveys, experiments or discourse analysis, empirical researchers have innovated methods in deliberation to understand the deliberative quality of structured forums. Take the case of Jürg Steiner and colleagues' updated work on Discourse Quality Index. Developed in 2004 to operationalise Habermas's discourse ethics to assess parliamentary debates (Steiner et al 2004), this approach is now updated to incorporate storytelling and its role in transforming the quality of deliberation (Steiner, Jaramillo, Mameli and Maia 2017). Meanwhile, there are also methodological attempts to decentre talk as the main indicator of deliberation and instead examine how listening or uptake unfolds in deliberation for participants to consider new perspectives and modes of communication (Scudder 2019; Curato 2019).

Second, empirical research in deliberative democracy has been ambitious in its scope. Experimental research in deliberation has provided scholarly credibility on how carefully designed forums can correct the pathologies of political communication, which, in turn serve as basis for promoting deliberative practice at various levels of democratic governance. For example, experimental studies on like-minded group discussion, whether online or face-toface, illustrate how discursive spaces can be designed to activate deliberative norms and overcome group polarisation (Strandberg, Himerloos, and Grönlund 2019). James Fishkin's latest experiment, American in One Room, speaks to this line of thinking, albeit from a different angle. America in One Room demonstrated how deliberation can overcome partisan politics, with Republicans becoming less punitive in their attitudes towards illegal migrants after taking part in focused deliberations with a statistically representative sample of Americans over a long weekend (Fishkin and Diamond, 2019). There is also increasing 
empirical research using experimental methods on the so-called 'gender gap in deliberation.' Feminist critiques have been some of the earliest challengers to deliberation, where women are assumed to be less willing to speak up compared to their male counterparts. There is evidence to suggest that women are willing to deliberate, although men's poor deliberative behaviour undermines women's capacity to be effective deliberators (Afsahi 2020a). Another experimental study, meanwhile, found that participants are more willing to change their views after hearing a male deliberator's counterargument, indicating the persistence of gendered inequalities in discourse (Beauvais 2019). These ambitious empirical studies, among others, provide a credible stock of knowledge for deliberative democracy to be assertive in practice. It empowers scholars and practitioners of deliberative democracy to identify design aspects of mini-publics where power differentials can be reduced, whether it is in facilitation, and incorporation of implicit bias training in deliberative processes, among others.

The ambitious scope of research is also manifested in the growing body of empirical work that investigate deliberation beyond structured forums. Taking the empirical focus beyond the controlled environment of deliberative mini-publics, scholars have been studying the role of media (Wessler 2019), social movements (Felicetti, 2016), or schools (Nishiyama 2017) in shaping the character of public deliberation. Empirical researchers have also studied deliberation in political contexts where it was previously deemed impossible, such as deeply divided societies (O'Flynn 2017), the aftermath of a tragedy (Curato 2019) or wars (De-Waal 2017). More recently, scholars characterise how deliberative democracy can be achieved on a large-scale by linking the virtues of small-scale deliberation to the larger-scale process of opinion formation and decision-making (Barvosa 2018; Parry 2019).

This expansive empirical focus, associated also with the systemic turn in the field, has yielded insights about the conditions under which large-scale deliberation is possible. Yet at the same time, it raised new empirical questions about where to draw the boundaries of a deliberative system (Owen and Smith 2015), and what methods would be suitable to study deliberative systems as a whole. One key challenge in this context has been to develop methods to measure deliberativeness at the systems level (Ercan et al 2017; Fleuss and Helbig 2020).

Deliberative democracy, as a growing research field, recognises that more work needs to be done in sharpening ways to assess deliberative practice. Is the field better off with a problembased approach to democracy, where the focus is not on the boundaries of a particular model of democracy on but on different kinds of problems that democracy should resolve (Warren 2017)? How can empirical research on the micro-politics of deliberation speak to the conceptual precision that deliberative theorists advocate? And how can deliberative research be more sensitive to exclusions, such as ableism and ageism (Afsahi 2020b; Nishiyama 2017)? Empirical work on deliberation likely engage these questions in more depth in the coming years.

\section{Conclusion}

In this review article, we characterised the state of deliberative democracy and described the field as one that has become assertive in practice, precise in theory, global in reach, and ambitious in empirical research. These field-defining characteristics provide reason to think that deliberative democracy can offer innovative solutions to democracy's enduring and 
emerging challenges. As deliberative democracy continues to evolve, long-standing questions remain unanswered and new criticisms emerge. We wrote this manuscript during the early stages of a global pandemic, when citizens are discouraged from assembling in large groups. This is yet another crisis that deliberative democracy needs to face, for it puts into question the role of embodied deliberation in democratic practice, the relevance of reflective reasongiving at a time when fast decisions are made by experts, and the future of democracy when society's vulnerabilities are constantly exposed. For deliberative democracy to continue to flourish, the state of the field continues to be true to its normative core and while finding innovative ways for meaningful democratic reform in a highly unequal, climate-challenged, and increasingly fragile global public sphere.

\section{References}

Achen, Cristopher H. and Bartels, Larry M. (2017). Democracy for realists: Why elections do not produce responsive government. Princeton: Princeton University Press.

Afsahi, A. (2020a). Gender Difference in Willingness and Capacity for Deliberation. Social Politics: International Studies in Gender, State \& Society.

https://doi.org/10.1093/sp/jxaa003

Afsahi, Afsoun (2020b). Disabled Lives in Deliberative Systems. Political Theory, 0090591720913093.

Ani, Emmanuel Ifeanyi (2014) On Traditional African Consensual Rationality. The Journal of Political Philosophy 22(3): 342-365.

Avritzer, Leonardo (2005) Modes of Democratic Deliberation: Participatory Budgeting in Brazil. In Boaventura de Sousa Santos (ed.) Democratizing Democracy: Beyond the Liberal Democratic Canon. New York: Verso, 377-404.

Bächtiger, André, Dryzek, John S., Mansbridge, Jane and Warren, Mark E. (eds.) The Oxford Handbook of Deliberative Democracy. Oxford: Oxford University Press.

Bächtiger, André and Parkinson, John (2019). Mapping and Measuring Deliberation: Towards a new deliberative quality. Oxford: Oxford University Press.

Barvosa, Edwina (2018) Deliberative Democracy Now: LGBT Equality and the Emergence of Large-Scale Deliberative Systems. Cambridge: Cambridge University Press.

Bohman, James (1998) Survey article: The coming of age of deliberative democracy. Journal of Political Philosophy 6(4): 400-425.

Brennan, Jason (2017). Against democracy. Princeton: Princeton University Press.

Chambers, Simone (2018a). Human life is group life: deliberative democracy for realists. Critical Review, 30(1-2), 36-48.

Chambers, Simone (2018b) The Philosophical Origins of Deliberative Ideals. In André Bächtiger, John S. Dryzek, Jane Mansbridge, and Mark E. Warren (eds.) The Oxford Handbook of Deliberative Democracy. Oxford: Oxford University Press. pp. 55-69.

Chung, Hun, and Duggan, John (2020). A Formal Theory of Democratic Deliberation. American Political Science Review, 114(1), 14-35.

Chwalisz, Claudia (2015). The populist signal: Why politics and democracy need to change. London: Rowman \& Littlefield International.

Curato, Nicole (2019) Democracy in a Time of Misery: From Spectacular Tragedy to Deliberative Action. Oxford: Oxford University Press.

De Waal, Alex (2017). Inclusion in peacemaking: From moral claim to political fact. In: Aall, Pamela and Croker, Chester (eds) The fabric of peace in Africa: Looking beyond the state, Waterloo On: Centre for International Governance Innovation. pp. 165-186. 
Dryzek, John S., André Bächtiger, Simone Chambers, Joshua Cohen, James N. Druckman, Andrea Felicetti, James S. Fishkin, David M. Farrell, Archon Fung, Amy Gutmann, Hélène Landemore, Jane Mansbridge, Sofie Marien, Michael A. Neblo, Simon Niemeyer, Maija Setälä, Rune Slothuus, Jane Suiter, Dennis Thompson, Mark E. Warren (2019) The crisis of democracy and the science of deliberation. Science 363(6432): 1144-1146.

Ercan, Selen A., Carolyn M. Hendriks and John Boswell (2017) Studying public deliberation after the systemic turn: the crucial role for interpretive research. Policy \& Politics, 45(2): 195-212.

Ercan, Selen A., Carolyn M. Hendriks and John S. Dryzek (2019) Public deliberation in an era of communicative plenty. Policy and Politics 47(1):19-36.

Farrell, David M., \& Suiter, Jane (2019). Reimagining Democracy: Lessons in Deliberative Democracy from the Irish Front Line. Ithaca: Cornell University Press.

Felicetti, Andrea (2016) Deliberative Democracy and Social Movements: Transition Initiatives in the Public Sphere. New York: Rowman \& Littlefield International

Fishkin, James and Diamond, Larry (2019) This Experiment Has Some Great News for Our Democracy. The New York Times. October 2. Available at: https://www.nytimes.com/2019/10/02/opinion/america-one-room-experiment.html

Fishkin, James S. (2018). Democracy when the people are thinking: Revitalizing our politics through public deliberation. Oxford: Oxford University Press.

Fleuss, Dannica and Helbig, Karoline (2020) Measuring Nation States' Deliberativeness: Systematic Challenges, Methodological Pitfalls, and Strategies for Upscaling the Measurement of Deliberation. Political Studies [Online first]

Gastil, John and Knobloch, Katie (2019). Hope for Democracy: How Citizens Can Bring Reason Back into Politics. Oxford: Oxford University Press.

Goodin, Robert E. (2018) If Deliberation Is Everything, Maybe It's Nothing. In André Bächtiger, John S. Dryzek, Jane Mansbridge, and Mark E. Warren (eds.) The Oxford Handbook of Deliberative Democracy. Oxford: Oxford University Press. pp. 900-912.

Goodman, R. 2018. The Deliberative Sublime: Edmund Burke on Disruptive Speech and Imaginative Judgement. American Political Science Review. Vol.112, No.2, pp.267-279.

Gormley, S. 2019. Deliberation, Unjust Exclusion, and the Rhetorical Turn. Contemporary Political Theory. Vol.18, pp.202-226.

Habermas, Jürgen (2006) Political Communication in Mass Society: Does Democracy Still Enjoy Epistemic Dimension? The Impact of Normative Theory on Empirical Research. Communication Theory 16(4):411-26.

He, Baogang and Warren, Mark E. (2011) Authoritarian Deliberation: The Deliberative Turn in Chinese Political Development. Perspectives on Politics 9(2): 269-89.

He, Baogang, \& Wagenaar, Hendrik (2018). Authoritarian deliberation revisited. Japanese Journal of Political Science, 19(4): 622-629.

Hébert, Martin (2018) Indigenous Spheres of Deliberation. In André Bächtiger, John S. Dryzek, Jane Mansbridge, and Mark E. Warren (eds.) The Oxford Handbook of Deliberative Democracy. Oxford: Oxford University Press. pp. 100-112.

Landemore, Hélène (2020) Open Democracy: Reinventing Popular Rule for the $21^{\text {st }}$ Century. Princeton: Princeton University Press.

Laydet, D. 2015. Partisan Legislatures and Democratic Deliberation. The Journal of Political Philosophy. Vol.23, No.3, pp.235-260

Lee, Caroline W. (2014) Do-it-yourself democracy: The rise of the public engagement industry. Oxford: Oxford University Press. 
LiPuma, Edwin and Thomas A. Koelble (2009). Deliberative democracy and the politics of traditional leadership in South Africa: A case of despotic domination or democratic deliberation? Journal of Contemporary African Studies 27(2): 201-223.

Mansbridge, Jane. 2015. A Minimalist Definition of Deliberation. Pp. 27-49 in Deliberation and Development, ed. Patrick Heller and Vijayendra Rao. Washington, DC: World Bank.

Mantena, Karuna (2012) On Gandhi's Critique of the State: Sources, Contexts, Conjunctures. Modern Intellectual History 9(3): 535-563.

Min, Seong-Jae (2009) Deliberation, East Meets West: Exploring the Cultural Dimension of Citizen Deliberation. Acta Politica 44(4): 439-458.

Moore, A. 2018. Anonymity, Pseudonymity, and Deliberation: Why Not Everything Should Be Connected. The Journal of Political Philosophy. Vol.26, No.2, pp.169-192.

Neblo, Michael A., Kevin Esterling and David M. Lazer (2018). Politics with the people: Building a directly representative democracy. Cambridge: Cambridge University Press. newDemocracy Foundation (2019) Enabling National Initiatives to Take Democracy Beyond Elections. Accessible at: https://www.newdemocracy.com.au/wpcontent/uploads/2018/10/newDemocracy-UNDEF-Handbook.pdf

Nishiyama, Kei (2017) Deliberators, not future citizens: Children in democracy. Journal of Public Deliberation 13(1): Article 1.

O’Flynn, Ian (2017) 'Pulling together: Shared intentions, deliberative democracy and deeply divided societies' British Journal of Political Science, 47(1): 187-202.

Owen, David and Graham Smith (2015) Survey Article: Deliberation, Democracy, and the Systemic Turn. Journal of Political Philosophy 23(2): 213-234.

Parry, Lucy J. (2019) Discourses on foxhunting in the public sphere: A Q methodological study. British Politics 14(3): 290-310.

Sanyal, Paromita and Vijayendra Rao (2018) Oral Democracy: Deliberation in Indian Village Assemblies. Cambridge: Cambridge University Press.

Sass, Jensen and John S. Dryzek (2014) Deliberative Cultures. Political Theory 42(1):3-25.

Scudder, Molly F. (2019). The Ideal of Uptake in Democratic Deliberation. Political Studies, 0032321719858270.

Sen, Amartya (2005) The Argumentative Indian: Writings on Indian History, Culture and Identity. London: Allen Lane.

Setälä, Maija and Graham Smith (2018) Mini-Publics and Deliberative Democracy. In André Bächtiger, John S. Dryzek, Jane Mansbridge, and Mark E. Warren (eds.) The Oxford Handbook of Deliberative Democracy. Oxford University Press, Oxford, 300-314.

Sintomer, Yves (2018) From Deliberative to Radical Democracy? Sortition and Politics in the Twenty-First Century. Politics and Society 46(3): 337-357.

Steiner, Jürg, Bächtiger, André, Spörndli, Markus and Steenbergen, Marco R. (2004). Deliberative Politics in Action: Analyzing Parliamentary Discourse. Cambridge: Cambridge University Press.

Steiner, Jürg, Maria Clara Jaramillo, Simona Mameli, and Rousiley CM Maia (2017) Deliberation across deeply divided societies. Cambridge: Cambridge University Press.

Strandberg, Kim, Himmelroos, Staffan and Grönlund, Kimmo. (2019) Do discussions in likeminded groups necessarily lead to more extreme opinions? Deliberative democracy and group polarization. International Political Science Review 40(1): 41-57.

Tan, Sor-hoon (2014) Early Confucian concept of Yi (议) and deliberative democracy. Political Theory 42(1): 82-105. 
Tanasoca, A. and Sass, J. 2019. Ritual Deliberation. The Journal of Political Philosophy. Vol.27, No.2, pp.139-165.

Urfalino, Philippe (2014). The Rule of Non-Opposition: Opening Up Decision-Making by Consensus. Journal of Political Philosophy 22(3): 320-341.

Warren, Mark E. (2017) A problem-based approach to democratic theory. American Political Science Review 111(1): 39-53.

Warren, Mark E. and Hilary Pearse (eds.) (2008) Designing Deliberative Democracy: The British Columbia Citizens' Assembly. Cambridge: Cambridge University Press.

Williams, Melissa S. and Mark E. Warren (2014) A Democratic Case for Comparative Political Theory. Political Theory 42(1): 26-57.

Wolkenstein, Fabio (2019). Rethinking Party Reform. Oxford: Oxford University Press. 